\title{
SWOT Analysis on the Paid Opening of University Sports Venues in Lanzhou
}

\author{
Yang Wang ${ }^{1, a}$ and Xiao Wang ${ }^{2, b}$ \\ ${ }^{1}$ School of Northwest Minzu University, Gansu 731000, China; \\ ${ }^{2}$ School of Gan Su Sheng Bao Yu Yuan, Gansu 731000, China; \\ a290050514@qq.com, ${ }^{b} 361887921 @ q q . c o m$
}

Keywords: Lanzhou university; Sports venues; The paid open; SWOT

\begin{abstract}
With the official opening of the university gymnasium in Lanzhou, the real issue of the normal operation of the gymnasium is mentioned on the agenda. I will use the SWOT analysis method, colleges and universities in Lanzhou sports venues open to the society are paid within the feasibility analysis and aimed at colleges and universities sports venues within the paid open puts forward some measures and proposals. Such as in the school sports teaching, training, on the basis of sports venues shall be paid for the management, reasonable operation for Lanzhou university sports venues, provides a favorable theoretical basis, in addition, through the further research of this project will also bring guidance for practical work.
\end{abstract}

\section{Introduction}

The distribution of university sports stadiums is an important infrastructure of the school, also an important guarantee for the smooth development of teaching work. In the normal circumstances, the gymnasium of the university is mainly for the school teachers and students to provide physical exercise, sports activities, sports competition venues. In recent years, vigorously promote the development of sports culture in our country, promoting the national fitness, which makes the sports resources of colleges and universities gradually into the development of the socialist market economy, colleges and universities in the use of sports venues are no longer limited inside the school teachers and students, and society paid open to the public will face new difficulties and challenges. This paper uses the method of SWOT, colleges and universities in Lanzhou sports venues to explore analysis, explore and suitable for the development of Lanzhou university sports venues management pattern, wide open to the public, better adapted to the increasing mass fitness demand, to support to promote the vigorous development of sports culture in China.

SWOT analysis is the situation analysis. Refers to the object of study of the internal advantage and disadvantage and external opportunities and threats, through investigation and study, will result in a matrix, and carries on the system analysis, finally the corresponding research conclusions. SWOT refers to the strengths and weaknesses of the research object, as well as external opportunities and threats. With SWOT analysis, it is able to systematically and accurately analyze the current situation of the research object, and then formulate the development strategy, plan and countermeasures.

\section{SWOT Analysis Is Used to Analyze the College Sports Venues in Lanzhou.}

Advantages of the paid opening of university sports venues in Lanzhou. Advantages of sports culture resources. The development of sports activities is easier to highlight the advantages of campus construction, and the campus sports culture resource is an important carrier of the development of sports culture. Campus sports culture contains material culture and spiritual culture resources, material and cultural resources including sports facilities, human resources, sports event planning scheme, sports information, etc., these are the necessary elements of carrying out sports activities, in addition to the spirit of the campus sports culture resources and contains the necessary knowledge, aesthetic, interest in sports training and orientation, etc. The author believes that these 
resource elements can provide some support and guarantee for the paid opening of university sports venues in Lanzhou.

Advantages of sports talents. Lanzhou college sports teachers is relatively strong, and has many powerful training team, can provide scientific and reasonable to people taking part in physical exercise of theoretical guidance and practical method, thus reducing the probability of events. Therefore, fully take advantage of Lanzhou university sports venues open to the society, giving full play to the advantages of sports talents, promote the development of Lanzhou sports, making the social and economic benefit, common development, to achieve "win-win".

The advantage of sports training atmosphere. As one of the national education base of talents training plan, Lanzhou university are to cultivate a group of professional sports talents with high quality, and cultivate talent is relatively fixed, the Lanzhou university in the professional sports training, good sports pedagogy and the psychology training of the teachers and students. In physical education and sports activities, sports, and many other aspects for other departments created good sports atmosphere, students and other members of the society also produce certain effect, promote the development of the national fitness program.

The sports consumption group has continuously expanded its advantages. With the successful hosting of the Olympic Games in Beijing, full access to the national fitness stage in our country, in the promotion and reform of the sports events also with each passing day, in the thirteenth session of the national sports meeting is set for the first time the crowd group game, let the public groups, sports fans are also involved in a national sports events, the indications are that the sports promotion and recognition are slowly accept, more and more people begin to switch to spiritual requirements, and material needs of life at the same time, with the deepening of the national fitness concept and national investment in the sports resources in colleges and universities make growing sports consumer groups, Not only was there an increase in the number of students and faculty, but also a significant increase in the number of people involved in sports.

Geographical advantages. Lanzhou university's unique geographical location and unique architectural style will attract more people to this consumption, fitness and entertainment.

\section{The Weakness of the Paid Opening of University Sports Venues in Lanzhou.}

The Market Subject is Immature. For the time being, the sports venues in the universities in Lanzhou are in the primary stage of operation, and the business model and social atmosphere of opening to the outside world are not yet formed. Maintenance of sports venues, managers and consumers' market main body is not yet mature, on the one hand, colleges and universities require a great deal of maintenance funds to maintain the normal operation of the venue, on the other hand, the general public also need high quality and high service useful place for sports consumption, but in terms of the status quo of Lanzhou, the two aspects of demand has not yet reached a consensus. Therefore, it is necessary to change the concept and consciousness of operators and sports consumers.

Imperfect Management System. Lanzhou university sports venues' main function is to provide teachers and students for the school sports exercise, sports activities and competition, has not developed into a large-scale management mode of enterprise management, also is on a path to industrialization management.

Lack of Professional Venue Management Personnel. For now, Lanzhou university major sports venues in the construction of fundamental purpose is to provide teachers and students in school sports exercise, sports activities and competition venues, to meet the needs of the everyday school sports teaching and training. Due to the lack of professional venues for sports venues management talent, lead to college sports venues within the more dependent on the school of government funding, from that Lanzhou college sports venues within the business model is not self-sufficient. Therefore, lack of professional sports operating companies, professional manager is the poor management of Lanzhou university sports venues, a big disadvantage, it also hindered the steps of the process of college sports venues open to the society paid.

Lack of Market Competitiveness. With the establishment of the socialist market economy in 
our country, for the production, exchange, distribution, consumption, must follow the rules of the socialist market economy, to achieve the optimal allocation of sports resources. Lanzhou university sports venue is still in the half open, and to form a perfect management mechanism and operation mode, it is decided to choose the market orientation and the lack of brand idea of serving the party, which led directly to the management and service quality and market demand does not match.

The Venue Function is Single, the Financial Burden is Heavier. For the Lanzhou stadium is given priority to with physical education teaching in colleges and universities, the operation of the maintenance cost is higher, so as to increase the financial burden of the school, so should develop its sports venues of other function, reduce the financial burden of the school.

\section{Opportunities for Paid Opening of University Sports Venues in Lanzhou.}

National Policy Support. In the "national fitness plan (2011-2015)" made clear that in holding the great banner of socialism with Chinese characteristics, carry out and implement the scientific outlook on development, to protect the rights and interests of the citizens to participate in sports fitness activities. We will energetically develop public sports, promote the building of a nationwide fitness service system, and lay the foundation for building a strong sports power. In 2015 to overall objectives are: sports fitness awareness to further strengthen urban and rural residents, and take part in physical exercise number increased significantly, obviously improve the physical quality, sports fitness facilities will be improved, the national fitness service system covering urban and rural areas. $\mathrm{Xi}$ general secretary also pointed out in 13th session of national sports meeting "to speed up the construction of sports power, dreams will hold sports power is closely related to the Chinese dream of positioning, integrate the sports implementation 'two one hundred' goal to design" in the old structure.

The Increase of Public Leisure Time. With the development of global economic integration, our society is gradually become life automation, electronic integration and information globalization, the progress of science and technology bring infinite convenience to our lives, which make us have more leisure time. How to spend the leisure time of the self is effective and beautiful, gradually becomes the public's standard of the quality of life. And to spend your leisure time in the high quality service stadium in exercise, not only the physical and mental relaxation and exercise, good experience to meet the people to improve the quality of life. All these provide a certain opportunity for the paid opening of university gymnasium.

Development Trend of Leisure Sports. With the development of our country socialist market economy, people's living standards improve, people's traditional way of life, great changes have taken place in people's life quality, the healthy body, the spare life of rich also had higher yearning and pursuit, and recreational sports application. The development of leisure sports requires more sports venues to provide more and better service for people.

The Growing Demand for Stadiums and Gymnasiums. With the slogan of the national fitness, entertainment, leisure sports, elderly sports and lifelong has become increasingly obvious, which means that the demand of the sports venues, and higher requirements for the quality of life and suggests the direction of the sports venues management in colleges and universities should be high quality, high service, high standards, this also provides the Lanzhou university sports venues open to the public a chance.

Improvement of Citizens' Cultural Quality. The 21 st century is the era of knowledge economy, the cultural quality of citizens from the previous several years had the very big enhancement, make more and more people realize the importance of sports, they spend money to buy health, go to the club to exercise, it also provides the Lanzhou university sports venues open to the public a chance.

\section{The Threat of Paid Opening of University Sports Venues in Lanzhou.}

Curing Pressure. College sports venues is the important part of teaching facilities, school is the school degree is the important embodiment of teaching resources, sports venues more maintenance cost of human resources, the school resources construction investment proportion is larger and 
require a part of the long-term investment. After opening to the society, there will be huge maintenance pressure, especially some fitness equipment, and how to reduce the pressure of maintenance will be a very difficult problem.

Influence of Bad Behavior of Society on Students. Due to consumption of sports population, including all kinds of people, they are not civilized behavior, behavior will cause bad effect to the broad masses of students, how to deal with this problem is the school sports venues for open must solve the problem.

Impact of Sports Consumption Level. Since China's reform and opening-up, urban residents consumption level has increased significantly, but total level of consumption in China compared with developed countries, there is still a large gap, especially in sports consumption. Therefore, the level of sports consumption will also have a certain impact on the form of paid opening of university sports venues in Lanzhou.

Damage to Campus Environment. Environment including learning environment and the natural environment of the campus, if not reasonable deal with the normal teaching and open time, will be on students' physical education learning, exercise caused certain effect, at the same time, due to the increase of traffic will also result a certain destruction to the natural environment.

The Campus Traffic Pressure, the People Increase. The university sports venues in Lanzhou are open to the public, which will inevitably increase the traffic burden and the flow of people in the campus. If improper handling, it will have a certain effect on the normal teaching.

\section{Discussion on the Mode of Paid Opening of University Sports Venues in Lanzhou.}

Cultivate a Team that Knows both Sports and Management and Improve the Quality of Management Personnel. As the management personnel of stadium, should have high management quality and management level. The quality level of management personnel will directly affect the industrial income and social benefit of university sports venues, and it will also be a factor that impedes the social opening of university sports venues. Many participate in sports venues management personnel at present, the lack of professional system management level and management experience, consciousness of market demand is not high, these defects will hinder the reform of university sports venues to the industrialization management and innovation. Therefore, it is an important task to pay more attention to the management quality and management level of the management personnel.

Improve the Management System. If the university sports stadium is to be open to the society, one of the important prerequisites should be to meet the needs of the teaching and training of the students and teachers in the university, so as to carry out the paid opening of the gymnasium. How to implement the paid open must have a set of perfect management system, and on the specific operation may be taken to all the teachers and students of the school of preferential policy, namely free exercise on campus, and for other people, should be based on cost accounting geared to the needs of the market, formulate reasonable charging standards.

Increase Marketing means to promote the Economic Benefits of Venues. As sports this cultural phenomenon with the practice of market economy, the marketization of sports venues will also be a necessity, sports venues will also be the big games, large entertainment program, through the open to the public, and many other ways to integrate into the market.

Build a Comprehensive Sports Service Center. The university gymnasium is open to the society to be paid to be open to the society means the need to build the gymnasium to be integrated sports fitness and recreation as one of the comprehensive sports service places. Fully excavate the potential advantages of university sports venues, to promote the development of the national fitness campaign, and to form a social atmosphere advocating the sunshine movement and advocating sports in the whole society.

\section{Conclusions}

The sports venues in the colleges and universities in Lanzhou have the advantages of high quality of 
infrastructure, good environment atmosphere and superior geographical environment compared with the social sports venues. However, there are still many disadvantages in terms of social paid opening. For example, the market subject is immature, the management system is not perfect, and the lack of professional venue management personnel and the single function of the venue are not sufficient.

The university sports stadiums have a rigid management, the idea of aging and so on. And maintenance of the venue by schools and more government funding, combined with the sports funds lags the growth level of education funds for a long time, can lead to the development of college PE process is often affected by lack of funding. In order to solve this contradiction, reasonable use of university sports venues, appropriate to the society paid open, will effectively alleviate the contradiction.

University sports venues open to society paid such a move, conforms to our country sports development objective request, is the response to the national call to advocate the national fitness, an effective measure to promote reform and development of sports culture in China.

The university sports venues in Lanzhou are still under threat, such as the pressure of maintenance, the damage to the campus environment and the traffic burden of the school.

\section{Suggestions}

Gradually cultivate mature market subjects, improve the construction of management mechanism, introduce high-quality venue management personnel and develop professional quality cultivation of field managers. Gradually form the industrialized management of college sports stadiums, so that the college sports venues can transform from single function to integrated service function integrating fitness, leisure and entertainment.

Emancipate the mind, change the concept, face the society, face the market, give full play to the advantages of universities and realize self-development. The paid opening of university sports venues should be controlled, and the profit funds should be used reasonably to promote the healthy development of sports in colleges and universities.

Reasonable coordination and moderate opening. The management and management of university gymnasium should hold the main time, always put the school teaching training in the first place, the leisure time and the statutory holidays can reasonably arrange the sports venues to be paid open.

Through open to society paid income of money and granted by the state of special funds to support, etc., on a regular basis to the venue for maintenance, and make strict regulations, standardize the uncivilized behavior, in order to strengthen the management of sports venues, promote the benign operation of the venue.

\section{References (In Chinese)}

[1] G. Chou and J.Y. Liu: Journal of Changchun University, (2004) No.5(1), p.59.

[2] State Council: China, National Fitness Program, (2011) No.5

[3] Y. Liu, M.M. Liu and Y. Shi: Journal of Tianjin Sports Institute, (2010) No.25(1), p.22.

[4] J.F. Zhao and D.G. Li: Fujian Sports Technology, (2007) No.26(6), p.29.

[5] F. Yu: Sports Scientific Research, (2005) No.26(2), p.90.

[6] S. Zou and B. Ca: Journal of Beijing Sports University, (1997) No.20(3), p.6.

[7] Y.H. Leng: Journal of Shanghai Sports Institute, (2005) No.29(6), p.21.

[8] G.Z. Ge: Journal of Changzhou Information Vocational College, (2008) No.7(6), p.90.

[9] G.Y. Liu and S.T. Wu: Journal of Sport, (2006) No.13(12), p.140. 